\title{
Gênero na Educação Infantil: análise dos planejamentos e do PPP de um núcleo de educação infantil de Florianópolis
}

Resumo: Neste artigo abordam-se as relações de gênero no campo da Educação Infantil. Inicialmente, realiza-se um estudo de caráter qualitativo, mais especificamente, uma pesquisa documental e bibliográfica. Em seguida, analisam-se os planejamentos de seis grupos da pré-escola e o Projeto Político-Pedagógico (PPP) de um núcleo de educação infantil de Florianópolis para entender como a temática de gênero é contemplada nos documentos oficiais da instituição. Os dados desta pesquisa apontam que só sete planejamentos concebem a equidade de gênero, considerando-se o número total de 57 planejamentos analisados. Dessa forma, identifica-se que tanto no PPP quanto nos planejamentos há a necessidade de se reconhecer e visibilizar a figura feminina, já que nas propostas pedagógicas a figura masculina é trabalhada e segue como referência. Nesta pesquisa constata-se que,para contemplar uma educação voltada para a equidade de gênero, é importante romper com os preconceitos, os papéis de gênero, os estereótipos sexuais, as práticas discriminatórias e a heteronormatividade na educação.

Palavras-chave: Gênero; Educação Infantil; Pré-escola; PPP; Planejamento.

\section{Gender in Children Education: analysis of planning and PPP of a Florianópolis children's education nucleus}

\begin{abstract}
This article deals with gender relations in the field of Early Childhood Education. Initially, a qualitative study was carried out, more specifically, a documentary and bibliographical research. Then, the plans of six preschool groups are analyzed and the Political-Pedagogical Project (PPP) of a center of early childhood education in Florianópolis to understand how the gender theme is contemplated in the official documents of the institution. The data of this research indicate that only seven plans conceive gender equity, considering the total number of 57 plans analyzed. Thus, is possible to identifie that both in the PPP and in the planning there is a need to recognize and make visible the female figure, since in the pedagogical proposals the masculine figure is worked and it follows like reference. In this research it is verified that, to contemplate an education focused on gender equity, it is important to break with the prejudices, gender roles, sexual stereotypes, discriminatory practices, and heteronormativity in education.
\end{abstract}

Keywords: Gender; Early Childhood Education; Preschool; PPP; Planning.

\footnotetext{
1 Especialista em Gênero e Diversidade na Escola, pela Universidade Federal de Santa Catarina. Graduada em Pedagogia pela UNIASSELVI. Professora de Educação Infantil na rede municipal de ensino de Florianópolis. E-mail: elisa-scher@hotmail.com

2 Doutora em Educação e Cultura pela Universidade de Osnabrueck, Alemanha (2010). Professora do Programa de Pós-Graduação em Educação na UNIPLAC/SC. Coordena o grupo de pesquisa Gênero, Educação e Cidadania na America Latina (GECAL/UNIPLAC). E-mail: mareligraupe@hotmail.com
} 


\section{Introdução}

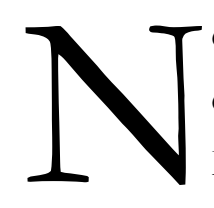

este artigo apresenta-se um recorte da monografia apresentada ao Curso de Especialização em Gênero e Diversidade na Escola (GDE), no período de 2015 a 2016, da Universidade Federal de Santa Catarina (UFSC). Nesse curso teve-se a oportunidade de construir conhecimentos sobre as práticas pedagógicas relacionadas às temáticas de gênero, diversidade e sexualidade no campo da Educação, especialmente no contexto social de mulheres, pessoas com deficiência, negras/os, índias/os, ciganas/os, homossexuais, bissexuais, lésbicas, transexuais, dentre outras categorias.

Nesse curso ampliou-se o conhecimento sobre educação de qualidade e respeito à igualdade de direito para todas as pessoas. Nesse aspecto é essencial estar atento para que o preconceito e a discriminação não se reproduzam e se constituam no espaço educacional. Daniela Finco (2010, p. 121) reafirma a importância dessa temática ao assegurar que "[...] o direito a uma educação infantil de qualidade inclui a discussão das questões de gênero". Sendo a Educação Infantil o espaço em que as crianças aprendem a se relacionar e conviver com outras crianças e adultos de diversas etnias, classes sociais, religiões, culturas, torna-se também um espaço privilegiado para a discussão de gênero.

É importante que se contemplem as discussões de gênero na Educação Infantil para que não seja reforçado um posicionamento que normatiza, disciplina e controla comportamentos infantis, reforçando estereótipos específicos para cada gênero.

Louro e Felipe e Goellne (2013, p. 44) elencam questões referentes às discussões de gênero, introduzindo a corporeidade e a sexualidade como meio para adentrar o tema em ambientes escolares e sociais, pois "Que olhar de mudança social não é apenas ao sujeito que é questionado, mas toda uma cultura, ciência, arte, ética, educação entre outros”.

Nesta pesquisa analisa-se como a temática de gênero é contemplada nos planejamentos quinzenais $^{3}$ de seis grupos da pré-escola e no Projeto Político-Pedagógico (PPP) de uma instituição de Educação Infantil da cidade de Florianópolis. Inicialmente, realizou-se a coleta de dados no mês de novembro de 2016, no Núcleo de Educação Infantil Campeche (NEI Campeche). Esse núcleo atende crianças de um até seis anos de idade e possui um grupo de profissionais composto de 34 professoras e dois professores, quatro professoras readaptadas, ${ }^{4}$ um funcionário readaptado de serviços gerais, três funcionárias de serviços gerais, um funcionário de serviços gerais e três cozinheiras.

\footnotetext{
${ }_{3}^{3}$ Planejamentos de professoras e professores de sala, professor auxiliar de ensino e de educação física.

${ }^{4}$ Readaptação é o deslocamento do servidor para exercer atribuições afins pertinentes a outro cargo, de grau de complexidade, especialização e responsabilidades compatíveis com a limitação que tenha sofrido em sua capacidade física ou mental, comprovada em inspeção por Junta Médica Oficial.
} 
Para analisar esses documentos, utilizaram-se como principais referenciais teóricos os textos produzidos por Scott (1995), Grossi (2000), Finco (2003, 2005, 2008, 2010), Louro (1997) Louro, Felipe e Goellne (2013), Felipe (1999, 2013), entre outros.

Para a realização da coleta de dados, escolheu-se a pesquisa documental, conforme descreve Campos (2004, p. 611):

No universo das pesquisas qualitativas, a escolha de método e técnicas para a análise de dados deve obrigatoriamente proporcionar um olhar multifacetado sobre a totalidade dos dados recolhidos no período de coleta (corpus), tal fato se deve, invariavelmente, à pluralidade de significados atribuídos ao produtor de tais dados, ou seja, seu caráter polissêmico numa abordagem naturalística.

Portanto, o autor chama a atenção para a importância da escolha - métodos e técnicas -, pois devem ser consideradas as várias formas de olhar um objeto no contexto de sua totalidade.

Considerando-se que a pesquisa documental foi realizada em uma unidade de Educação Infantil da rede municipal de Florianópolis, foram contemplados alguns documentos desse município que buscam auxiliar e nortear o atendimento pedagógico da Educação Infantil. São eles: Diretrizes Educacionais Pedagógicas para a Educação Infantil, Diretrizes Curriculares da Educação Básica da Rede Municipal de Florianópolis, Orientações Curriculares para a Educação Infantil da Rede Municipal de Ensino de Florianópolis e Currículo da Educação Infantil.

\section{Gênero e Educação}

É na Educação Infantil que se iniciam o convívio e a socialização da criança em espaços coletivos. Conforme descreve a Lei de Diretrizes e Bases da Educação Nacional, no seu artigo 29, a Educação Infantil - primeira etapa da educação básica - " [...] tem por finalidade o desenvolvimento integral da criança até seis anos de idade, em seus aspectos físico, psicológico, intelectual e social, completando a ação da família e da comunidade" (BRASIL, 1996). De acordo com a LDB, a proposta da Educação Infantil deve trabalhar o desenvolvimento integral da criança; sendo assim, compete às professoras e aos professores enfatizar o trabalho com a totalidade das potencialidades infantis, entendendo que é indispensável abordar as relações de gênero no campo educacional.

A Proposta Curricular de Santa Catarina (SANTA CATARINA, 2014, p. 61) descreve que na educação básica é necessário “[...] superar os padrões estereotipados das relações de gênero e do modelo familiar único, pautado na família nuclear". Dessa maneira, discorre sobre a importância dos diversos arranjos familiares, reconhecendo que não existe um único modelo a ser seguido e imposto pela sociedade. Além desse aspecto, afirma que devem ser superados os padrões estereotipados que surgem no contexto escolar, ampliando uma discussão de gênero, com vistas ao entendimento das identidades de gênero como expressões legítimas e existenciais da vida dos sujeitos.

As Diretrizes Educacionais Pedagógicas para a Educação Infantil reconhecem as crianças como seres humanos concretos e reais pertencentes a contextos sociais e culturais que as constituem. E, quanto 
a esse processo de construção social, as Diretrizes citam que "[...] a infância deve ser reconhecida em sua heterogeneidade, considerando fatores como classe social, etnia, gênero, religião, como determinantes da constituição [...]" (FLORIANÓPOLIS, 2010, p. 13).

Os princípios fundamentais, segundo as Diretrizes Curriculares Nacionais para a Educação Infantil, são

Éticos: da autonomia, da responsabilidade, da solidariedade e do respeito ao bem comum, ao meio ambiente e às diferentes culturas, identidades e singularidades.

Políticos: dos direitos de cidadania, do exercício da criticidade e do respeito à ordem democrática.

Estéticos: da sensibilidade, da criatividade, da ludicidade e da liberdade de expressão nas diferentes manifestações artísticas e culturais. (BRASIL, 2010, p. 18).

De acordo com as Diretrizes, as propostas pedagógicas devem cumprir e oferecer condições para que as crianças possam usufruir de seus direitos civis, humanos e sociais, respeitando a igualdade de oportunidades e a construção de novas formas de sociabilidade.

Porém, ainda se observam nas unidades de Educação Infantil professoras e professores que articulam suas propostas de maneira diferente do que encaminham os documentos, visto que a organização, muitas vezes, é feita com a separação de meninas e meninos, por exemplo, quando a professora e/ou o professor conta quantas meninas e quantos meninos estão presentes em sala e, ao final, dá a soma total.

Dessa maneira, deve-se compreender como essa concepção de feminino e masculino interfere nas ações e nas relações de professora e/ou professor com as crianças no espaço da Educação Infantil no que se refere a valores, crenças e opiniões. A criança necessita desfrutar da autonomia para criar seus valores, tomar posições e ampliar seu universo de conhecimentos. Nesse sentido, Nunes e Silva (2000, p. 106) dizem que a professora e/ou o professor precisa constantemente "[...] fazer a crítica dos papéis tradicionais e de suas convicções ideológicas".

É de suma importância que as professoras e os professores possam agir de maneira a romper com as relações de dominação, principalmente aquelas relacionadas aos papéis de gênero na sociedade. Como exemplos, pode-se citar o comportamento que se exige das meninas, que devem gostar de brincar com panelinhas, bonecas e de casinha, de maneira a serem motivadas à maternidade e a cuidar do lar e da família. Da mesma forma, pode-se citar o comportamento exigido dos meninos, que devem gostar de brincar com carrinhos, de bombeiro, polícia, caminhão, brincadeiras diretamente ligadas a profissões, imputando a ideia de que ao homem cabe a função de trabalhar para sustentar a sua família.

Outro ponto importante a ser destacado sobre as relações de gênero na Educação Infantil é a relevância de serem trabalhados os papéis de gênero e os estereótipos, já que nesse espaço educativo se encontram símbolos e códigos, assim como a afirmação do que cada um pode ou não fazer.Muitas vezes, nesse espaço se agrupam, separam e normatizam comportamentos, valores e crenças sexistas e discriminatórias, enclausurando a criança e desconsiderando o respeito às diferenças.

A variedade dos brinquedos e as diversas opções de brincadeiras favorecem para que todos os espaços sejam ocupados por meninas e meninos indiscriminadamente. As 
crianças brincam espontaneamente com os brinquedos que escolhem sem constrangimentos. Meninos participavam de brincadeiras como cuidar da casa, cozinhar, passar roupa, cuidar dos filhos, que são vistas como funções das mulheres, assim as crianças trocavam e experimentavam os papéis de gênero durante os momentos de brincadeira. (FINCO, 2005, p. 9).

Finco (2005) aponta em seu artigo que o espaço e as propostas pedagógicas na Educação Infantil não devem ser marcados por movimentos que contemplem o gênero da criança, e sim que possibilitem à criança vivenciar e experimentar os diversos papéis de gênero; os estereótipos ligados aos papéis sexuais predeterminados são representações, na maioria das vezes, das relações dos adultos, que buscam encaminhar para a cultura da criança o masculino ou o feminino.

Assim como os outros documentos norteadores da educação infantil citados, o Currículo da Rede Municipal de Florianópolis (FLORIANÓPOLIS, 2015a, p. 68) descreve que na Educação Infantil devemse "[...] proporcionar brincadeiras diversas e jogos, através da organização do espaço, de brinquedos, de objetos e enredos, de modo que meninos e meninas tenham possibilidade de experimentar diferentes brincadeiras, independentemente do sexo". Sendo assim, é importante compreender de que maneira acontecem as propostas pedagógicas na unidade de Educação Infantil.

A discussão de gênero na Educação Infantil possibilita que tanto as meninas quanto os meninos possuam o direito de escolher suas brincadeiras, optar por quais papéis desejam apresentar e entender como se descobrir nesse processo de desenvolvimento e aprendizagem. Da mesma maneira, a discussão de gênero afirma que os padrões heterossexuais não são os únicos vivenciados na sociedade e que a identidade de gênero não é atribuída conforme o sexo biológico. Portanto, não se trata apenas de conviver com a pluralidade e a diferença, mas considerar que a humanidade se organiza e se estrutura a partir da diferença.

Sendo assim, as unidades educativas deveriam articular e criar meios para lidar com as diferenças e combater a reprodução dos valores hegemônicos relacionados à heterossexualidade e à sexualidade dos sujeitos. Direcionar o olhar para a diversidade é fundamental para compreender como a sociedade reproduz um comportamento excludente. Bento (2011, p. 558) descreve: "[...] ou você tem pênis ou vagina. Ou você é mulher ou é homem. Ou você é masculino ou feminino, mas sejamos todos heterossexuais. Nada de ambigüidade, um horror a indeterminação”.

$\mathrm{Na}$ Educação Infantil as crianças representam diversos papéis sociais vivenciados no meio social de que participam e buscam reproduzir os modos estabelecidos sobre ser mulher e ser homem como forma de regulação social através de brincadeiras e imaginário, como Sabat (2001) defende em seu artigo. Segundo a autora, a "pedagogia cultural"5é reforçada pelas mídias por meio da publicidade e constitui certas relações de poder.

\footnotetext{
${ }^{5}$ Segundo a qual, ensina-se através das imagens. A pedagogia cultural compreende signos produzidos socialmente pela cultura específica, os quais produzem valores e saberes; regulam condutas e modos de ser; fabricam identidades e representações; e constroem e constituem identidades culturais hegemônicas (SABAT, 2001).
} 
Dessa forma, acredita-se que o planejamento 6 das atividades pedagógicas na Educação Infantil precisa contribuir com o desenvolvimento das crianças, como indica a LDB n. 9.394/96, Art. 13, Incisos II e V. De acordo com a Lei, cabe aos docentes a tarefa de "[...] elaborar e cumprir plano de trabalho, segundo a proposta pedagógica do estabelecimento de ensino", da mesma maneira que esse plano não se encerra na forma sistematizada. Segundo as Diretrizes Educacionais Pedagógicas para a Educação Infantil, é preciso

Pensarmos um planejamento que contemple atividades intencionais, em momentos de ações, ora estruturadas, ora espontâneas e livres, demanda da supervisão um olhar atento sobre as crianças e seus lugares, assim como o papel e o lugar dos profissionais nestes diferentes momentos, constituindo-se num desafio para quem coordena a ação do planejamento dos tempos, dos espaços, dos materiais e dos projetos. (FLORIANÓPOLIS, 2010, p. 100).

É nesse sentido que o planejamento sinaliza e cita as crianças como atores principais das propostas pedagógicas, sendo importante nesse contexto que as professoras e/ou os professores desenvolvam dinâmicas nas suas práticas educacionais de modo a contemplar a interação e a socialização das crianças como protagonistas nesse processo pedagógico.

Entende-se que a temática das relações de gênero está presente no contexto escolar, seja na disputa por um brinquedo, em brincadeiras ou até mesmo na rotina de organização, nas conversas coletivas ou individuais com outra criança. Contemplar gênero na pré-escola significa ficar atento quando o assunto se torna sexista, quando um dos gêneros apresenta superioridade sobre o outro para degradá-lo. Da mesma forma a atenção é necessária quando o ato sexista parte de professoras e professores, quando enquadram tais comportamentos ou condutas sobre o masculino e o feminino.

Conforme aponta Finco (2003, p. 7):

Observando vários momentos de brincadeira foi possível levantar a hipótese de que as crianças ainda não possuem práticas sexistas em suas brincadeiras e, portanto, não reproduzem o sexismo presente no mundo adulto. Esses meninos e meninas ainda não possuem o sexismo da forma como ele está disseminado na cultura construída pelo adulto: as crianças vão aprendendo a oposição e a hierarquia dos sexos ao longo do tempo que permanecem na escola.

As crianças reproduzem nas unidades educativas os valores culturais de suas familias, os quais, muitas vezes, são apresentados em comportamentos sexistas, quando dizem que meninas somente devem brincar de bonecas e meninos de carrinhos, entre outros. Muitas crianças trazem consigo esses estereótipos de gênero de seus lares e, nesse sentido, a professora e/ou o professor busca interferir explicando que não existe brincadeira determinada para cada sexo, o processo de escolher com o que ou com quem brincar faz parte do processo de aprendizagem e interação.

$\mathrm{Na}$ Educação Infantil também se reproduzem os papéis de gêneros tradicionais controlados e reforçados pelas professoras e pelos professores, principalmente na organização do espaço da sala e nas interações, o que acaba moldando o comportamento infantil, estereotipando segundo o sexo e hierarquizando conforme os padrões sociais estabelecidos.

${ }^{6}$ Para aprofundar o conceito de planejamento, indicam-se as pesquisas de Sônia Kramer (2005) e Esmeralda Ostetto (1992). 


\section{Equidade de gênero e educação}

Para compreender a equidade de gênero na sociedade, é necessário traçar uma linha de estudo por volta do século XIX, quando surge a primeira onda feminista no Brasil. Nessa época as mulheres reivindicavam seus direitos, entre eles o do voto, o da vida pública e o de trabalhar sem a autorização do marido. A segunda onda deu-se no início da década de 1970, quando as mulheres passaram a lutar pela valorização do trabalho e pelo direito ao prazer sexual, sem violência ou contra a sua vontade. Na terceira onda, ${ }^{7}$ que teve início na década de 1990, as mulheres começaram a discutir os paradigmas estabelecidos nas outras ondas, colocando em pauta a micropolítica relacionada a grupos e/ou pessoas.

Conforme descreve Scott (1994, p. 25):

Um conceito relativizado de gênero como um saber historicamente específico sobre a diferença sexual permite às feministas forjar um instrumento analítico duplamente afiado, que permite gerar um saber novo sobre as mulheres e sobre a diferença sexual e inspirar desafios críticos às políticas da história ou, também, de qualquer outra disciplina. A história feminista deixa então de ser apenas uma tentativa de corrigir ou suplementar um registro incompleto do passado, e se torna um modo de compreender criticamente como a história opera enquanto lugar da produção do saber de gênero.

Scott (1994) explica em seu livro que as relações de gênero aparecem na história por meio das reivindicações das mulheres ${ }^{8}$ (feministas) por igualdade de direitos, mas aponta para os modos da hierarquização de práticas excludentes que aconteciam na sociedade visando à diferença sexual. Assim, foi possível apontar a política e a história, as quais abriram caminhos para a mudança.

O conceito de gênero surgiu entre as estudiosas feministas para se contrapor à idéia de essência, recusando assim qualquer explicação pautada no determinismo biológico, que pudesse explicar os comportamentos de homens e mulheres, empreendendo, desta forma, uma visão naturalizada, universal e imutável dos comportamentos. Tal determinismo serviu muitas vezes para justificar as desigualdades entre ambos, a partir de suas diferenças físicas. O que importa, na perspectiva das relações de gênero, é discutir os processos de construção ou formação histórica, lingüística e social, instituídas na formação de mulheres e homens, meninas e meninos. (FELIPE, 1999, p. 3).

As discussões de gênero não se enquadram somente no estudo das mulheres na sociedade nem se limitam somente a esse estudo, mas também abordam a construção social pela qual mulheres e homens, meninas e meninos são formados, uns com os outros, tanto como classe social, religião, etnia, nacionalidade etc.

Conforme afirma Grossi (2000, p. 5), "Gênero serve, portanto, para determinar tudo que é social, cultural e historicamente determinado. No entanto, como veremos, nenhum indivíduo existe sem relações sociais, isto desde que se nasce". Sendo assim, gênero remete à relação da identidade dos sujeitos, podendo esses apresentarem várias identidades que vão além da nacionalidade, da etnia, da idade etc.

\footnotetext{
7 Em 1994, inúmeros grupos feministas e centenas de grupos de mulheres se organizaram com o objetivo de criar uma rede de cooperação para a preparação da IV Conferência Mundial das Mulheres; a participação unificou o movimento de mulheres independentemente das diferenças ideológicas e políticas (SOARES, 1998).

${ }^{8}$ Mais informações, consultar Mello (2010), Michel (1982) e Pinto (2003).
} 
Essas identidades não são fixas ou inatas, ao contrário, são construídas e reconstruídas nas relações sociais e de poder exercidas por diversas instituições presentes na sociedade.

Da mesma maneira, as crianças desde o seu nascimento vão identificando seu gênero, seja pela influência das relações sociais e/ou culturais, através da família, da escola, da igreja e de demais instituições, as quais fazem parte desse processo de construção.

No entanto, diante do contexto social, Louro (1997) descreve que a escola tem se preocupado ao longo dos anos em "disciplinar e normalizar os indivíduos", sendo, portanto, um dos principais meios de regulação e formação de identidades. Partindo desse ponto, Finco (2008, p. 1) aponta que

É importante que os/as docentes que trabalham na Educação Infantil tenham consciência do potencial que o ambiente coletivo de educação tem para possibilitar a convivência entre a diversidade e repensem, desse modo, suas práticas educativas. A discussão das questões de gênero na educação infantil se traduz na possibilidade de uma educação mais igualitária, que respeite a criança na construção de sua identidade e que favoreça, desde as primeiras relações, a constituição de pessoas sem práticas sexistas. Demandam a incorporação de práticas educativas que introduzam conscientemente, como estratégia de socialização, a meta de igualdade de gênero.

Trabalhar a equidade de gênero na Educação Infantil compete em estar atento para intervir e combater qualquer discriminação sexista, e questionar e evitar os estereótipos ligados ao gênero na rotina, seja nas brincadeiras ou no comportamento de meninas e meninos aprendendo a respeitar o outro e as diferenças individuais.

\section{Núcleo de Educação Infantil Campeche: análise do PPP e dos planejamentos}

Primeiramente, inicia-se a análise dos documentos do NEI Campeche com a leitura do PPP e, posteriormente, dos planejamentos e dos registros que foram elaborados pelas professoras regentes de cada grupo. Por último, foram lidos os planejamentos e os registros das professoras e dos professores auxiliar de ensino e de educação física.

Para entender melhor o que é um Projeto Político-Pedagógico (PPP), foi feito um breve resumo de seu contexto e surgimento na Educação. A partir da década de 1980, o termo "projeto políticopedagógico" foi utilizado como uma forma de afirmar a natureza política do projeto educacional e contrapor a uma visão burocrática e técnica do projeto em si. Com o tempo, o termo vem conquistando bases legais que o regem em instâncias federal e estadual, por meio da Lei de Diretrizes e Bases n. 9.394, de 20 de dezembro de 1996.

Com isso, entende-se que a LDB n. 9.394/96 levanta a questão de construir o PPP reconhecendo na instituição a capacidade de planejar e organizar as suas ações pedagógicas e políticas em uma gestão participativa, ou seja, envolvendo todos os sujeitos participantes da comunidade escolar.

Entre as definições do PPP, é possível destacar que

É o plano global da instituição. Pode ser entendido como a sistematização, nunca definitiva, de um processo de Planejamento Participativo, que se aperfeiçoa e se objetiva na caminhada, que define claramente o tipo de ação educativa que se quer 
realizar [...]. Trata-se de um importante caminho para a construção da identidade da instituição. É um instrumento teórico-metodológico para a transformação da realidade. (VASCONCELLOS, 2004, p. 17).

Para Vasconcellos (2004), o PPP existe para várias finalidades, entre elas o regaste da intencionalidade da ação para assim possibilitar a (re)significação do trabalho; o instrumento de transformação da realidade; o envolvimento de pessoas em busca do mesmo objetivo; e o fortalecimento do grupo para enfrentar conflitos e divergências. Essas finalidades contribuem com a continuidade da linha de trabalho na instituição.

Dessa maneira, compreende-se que o PPP é um instrumento teórico-metodológico que exige uma sistematização e elaboração, devendo ser disponibilizado, construído e reconstruído por todos aqueles que participam da comunidade escolar.

O projeto político-pedagógico é um documento sistematizado que apresenta a organização do trabalho pedagógico da unidade educativa. Dessa maneira, cada uma possui o documento com as suas especificidades, devendo conter dados da unidade e da comunidade escolar, além de apresentar, juntamente com os documentos norteadores da educação, as suas propostas pedagógicas.

De acordo com as Diretrizes Educacionais Pedagógicas para a Educação Infantil,

[...] o PPP é um instrumento que subsidia as reflexões do grupo, aponta a direção do trabalho a ser realizado, documenta a trajetória histórica e educativa pedagógica da UE, informa a comunidade sobre como se organiza o trabalho. O projeto deve revelar o que o grupo pensa, realiza, ou deseja realizar, ou seja, é multifacetado. (FLORIANÓPOLIS, 2010, p. 95).

Sendo assim, o PPP é um documento que orienta e apresenta o trabalho pedagógico, sendo construído coletivamente com a comunidade escolar e familiar da unidade. Expressando uma gestão democrática e pedagógica, o PPP é fundamentado nos documentos oficiais, como a LDB, as diretrizes nacionais, o ECA, a Lei do Sistema e as resoluções, assim como em questões atuais da política pública para realizar um trabalho em parceira coletiva e coerente com os aspectos baseados no princípio da ética e da cidadania.

No PPP do NEI Campeche foram observados alguns pontos importantes e que merecem destaque sobre equidade de gênero. Ao se referir ao quadro de funcionários e funcionárias, apesar de o quadro ser, em sua maioria, preenchido por mulheres, o documento trata apenas de "professor" e “funcionários” nas orientações e na descrição.

O Manual para uso não sexista da linguagem, escrito por Cervera Paki Venegas Franco e Julia Pérez Cervera, preparado no e para o México, teve o original impresso em 2006 e a edição em português realizada com o apoio da Rede de Educação Popular entre Mulheres da América Latina (Repem) para ser distribuída pela internet para o Brasil e os países africanos de língua portuguesa.

Cervera Paki Venegas Francoe Julia Pérez Cervera (2006, p. 26) apontam:

Se levarmos em conta o anterior, podemos então concluir que quando se utiliza o masculino para nomear uma mulher ou um grupo de mulheres, seja involuntariamente ou por costume, estamos pelo menos tornando invisíveis as mulheres e, no pior dos casos, estamos excluindo-as da representação simbólica e real da sociedade que a língua produz. 
A busca pelos direitos ainda é uma luta travada para as mulheres na sociedade, apesar de compreender que desde o século XIX muitas conquistas foram alcançadas por meio dos movimentos sociais feministas. Cabe aos responsáveis pela atualização do PPP estar atentos e visibilizar os gêneros na escrita, buscando a equidade de gênero. Da mesma maneira, foi observado o uso da linguagem representando apenas o gênero masculino ao citar e/ou apontar as crianças apenas como filhos, excluindo, de certa maneira, as filhas. Assim destaca-se a importância de se denominarem palavras que não expressem o feminino ou o masculino ou, se assim for, lembrar de direcionar os dois gêneros: eles e elas.

Porém, ao longo da análise do PPP, foi possível observar o uso da palavra "família" para explicar e relacionar os integrantes das famílias, sem distinguir pai, mãe, entre outros. Da mesma forma, não são apontadas as datas comemorativas, sobretudo as festas do Dia das Mães e dos Pais. A Festa das Famílias, segundo o PPP, “[...] é para reunir, encontrar, confraternizar e valorizar as diferentes culturas e constituições familiares, considerando nossa comunidade e suas localidades de origem, bem como a localidade de moradia atual, as diversas formas de organização social” (FLORIANÓPOLIS, 2016, p. 26).

Esse registro, conforme consta no PPP, deu-se em consequência a uma pesquisa realizada com as famílias e com o grupo de estudo formado com as profissionais e os profissionais do NEI Campeche no ano de 2016, quando iniciaram os encontros das Festas das Tradições e da Família.

Assim, têm-se famílias estruturadas sob as mais diversas organizações, desde o patriarcalismo, o matrimonialismo, a monoparentalidade, a união estável e também a união homoafetiva. A Constituição Federal de 1988 trouxe grandes transformações na regulamentação da entidade familiar, legitimando a união estável, oferecendo maior consolidação da família, sob suas variadas modalidades, e principalmente ampliando o conceito de entidade familiar. (FLORIANÓPOLIS, 2016, p. 26).

Observa-se que a estrutura familiar nos dias atuais não é mais composta apenas de pai e mãe, há famílias compostas de casais homossexuais, assim como famílias de avós e avôs, famílias em que existe a presença só do pai ou da mãe, entre outras estruturas. Em virtude disso, é importante entender que todos têm direito a compor uma família, sendo isso contemplado no PPP, ou seja, o documento busca uma perspectiva de respeito à diversidade familiar, conforme preconiza a Constituição Federal de 1988.

Contudo, encerra-se a pesquisa no PPP do NEI Campeche sem localizar dados que descrevam alguma discussão de gênero que ampare a equidade de gênero no espaço educativo e nas propostas pedagógicas.

No segundo momento, quando da análise dos planejamentos, objetivou-se identificar como a equidade de gênero foi contemplada nesses documentos. No NEI Campeche existem seis grupos de préescola, três atendidos no período matutino e três no vespertino, sendo eles nomeados de Grupo 6 (G6), Grupo 6/5 (G6/5), Grupo 5/6 (G5/6), Grupo 6 (G6), Grupo 5 (G5) e Grupo 5/4 (G5/4).9

Foram feitas a leitura e a análise do planejamento de cinco grupos da pré-escola. Apesar de terem na unidade seis grupos, a pasta arquivo do Grupo 6/5 não estava disponível para análise.

\footnotetext{
9 Os Grupos 6 atendem crianças que já têm cinco anos completos; o Grupo 6/5 é um grupo misto que atende crianças com quatro e cinco anos; o Grupo 5/6 é um grupo misto que atende crianças com quatro e cinco anos; o Grupo 5 atende crianças que já têm quatro anos completos; e o Grupo 5/4 é um grupo misto que atende crianças com três e quatro anos completos.
} 
Conforme consta em seu PPP (FLORIANÓPOLIS, 2016, p. 46), o planejamento é um recurso importante, pois ajuda a organizar o tempo, o espaço, os materiais, as atividades. Em virtude disso,

[...] podemos dizer que quando planejamos tentamos garantir a presença de várias dimensões importantes que norteiam nossa ação pedagógica como, por exemplo: o tempo para falar, para ouvir, brincar, ler histórias, desenhar, comer, descansar e escutar as crianças de forma a promover o contato com o conhecimento legitimado e a cultura. O planejamento é um instrumento que ajuda na organização do diálogo entre as expressões infantis e a cultura vigente. Ele deve ser elaborado com intencionalidade, ou seja, deve conter as escolhas e caminhos que fazemos levando em conta as concepções de criança, infância e de Educação Infantil. $O$ planejamento deve ser pensado e elaborado levando-se em conta tudo o que acontece no cotidiano e não apenas os momentos de atividades onde se pressupõe que se está sendo ensinado algum conteúdo.

Sendo assim, o planejamento é um plano de ação que propõe práticas pedagógicas, pensando as crianças nas mais diferentes dimensões. Compreender que a criança é sujeito histórico social permitiu ao NEI Campeche que pudessem ser ministradas diversas propostas pedagógicas, contribuindo com a sua formação sociocultural.

O planejamento no NEI Campeche, segundo o PPP da Instituição, “[...] é um plano antes da ação e o pedagógico que permeia todas as ações que fizemos para e com as crianças" (FLORIANÓPOLIS, 2016, p. 29). Essa ação possibilita repensar momentos do cotidiano, ampliando a compreensão da prática e percebendo o grupo e seu movimento na intenção de levantar questionamentos sobre o que é preciso melhorar.

No NEI Campeche o planejamento das atividades pedagógicas das professoras segue as orientações que foram pensadas e elaboradas no ano de 2014, as quais são descritas na sequência.

Deve ser entregue quinzenalmente pelos professores de sala (primeira e terceira semana do mês);

Deve ser entregue quinzenalmente pelos professores auxiliares e professores auxiliares de educação especial (segunda e quarta semana do mês);

Deve ser entregue mensalmente pelos professores de educação física considerando as diferentes idades atendidas;

Ter intencionalidade (que se refere a ou com intenção: realizado de propósito; feito propositalmente; intencionado, crítica intencional);

Objetivos específicos ao que se propõe;

Coerência e continuidade com as propostas;

Propostas significativas e integradas utilizando os NAP'S como eixo norteador e de forma indissociável;

Descoberta e conhecimento do próprio corpo, atenção aos aspectos biológicos de seu funcionamento (cuidados, saúde e bem-estar), ou seja, a aprendizagem do auto-cuidado, assegurando que a rotina não seja mecânica e sim pedagógica;

Considerar as crianças e as famílias incrementando as relações sociais e afetivas (diálogo, troca entre adultos e crianças, expressão de afetos e sentimentos);

Desenvolvimento da autonomia;

Considerar os avanços e retrocessos e o papel do professor;

Estrutura metodologicamente;

Reverenciar bibliograficamente. (FLORIANÓPOLIS, 2016, p. 29).

Diante da organização do planejamento, é possível observar os objetivos e as ações que são específicos dos projetos elaborados de cada grupo. O planejamento é a forma de dar continuidade às propostas do projeto. 
Segundo o PPP do NEI Campeche (FLORIANÓPOLIS, 2016, p. 31), "Deve-se considerar que a escrita propicia ao professor uma reflexão mais aprofundada sobre o que foi vivido, oportunizando observações mais detalhadas sobre seu planejamento e a forma como ele e as crianças vivenciaram o mesmo". Sendo assim, o registro, o planejamento e a observação da professora e do professor são os meios utilizados para dar seguimento e visibilidade à criança diante da proposta.

Da mesma maneira, o PPP do NEI Campeche descreve que o registro pode ser escrito, fotográfico, em áudio, filmico etc. Não precisa ser extenso nem contemplar todas as crianças, mas documentar situações ricas em elementos para a construção da prática educativo-pedagógica e apontar algumas crianças.

A pesquisa permitiu a leitura de 10 planejamentos e oito registros do Grupo 5/6 matutino; e 13 planejamentos e 14 registros do Grupo 5/4 vespertino, os quais tinham como projeto a "Família", elaborado pela professora regente de sala. Nessa pesquisa propostas relacionadas às questões de gênero foram apontadas, entre elas algumas que permitiam conhecer o enredo familiar das crianças e as concepções que foram dialogadas no espaço da sala (conforme descrevem o planejamento e o registro), de maneira a contemplar os modelos familiares e o respeito ao núcleo familiar de cada criança e suas particularidades.

A análise do planejamento dos grupos 5/6 e 5/4permitiu compreender que as crianças conheceram o núcleo familiar de cada um dos colegas das salas (com visitas) e, nesse sentido, não foram identificadas nos planejamentos e nos registros propostas sobre as relações homoafetivas ou outros arranjos familiares que não fossem apenas de mãe e pai.

No período vespertino o Grupo 5 continha sete planejamentos e oito registros. O projeto do grupo foi sobre "Deusas e deuses da Mitologia Grega", que contemplou a discussão de gênero no enredo ao identificar nas propostas pedagógicas figuras mitológicas femininas e suas ações na Grécia Antiga.

Conforme consta nos planejamentos e nos registros, foram elaborados propostas e diálogos a respeito do matrimônio e da obrigação de as mulheres se casarem e procriarem, ou seja, gerarem filhos e filhas. Abordar no contexto da educação infantil os papéis de gênero desmistifica os padrões heteronormativos, os quais obrigam o casamento e a maternidade na sociedade.

O planejamento que contemplou o mito da Medusa, uma deusa com grande beleza que, após ser castigada, modificou sua expressão, abordou a figura feminina. Medusa, apesar das diferenças, ainda era reconhecida por seu poder de petrificar quem buscasse olhar em direção aos seus olhos, e não mais por sua beleza.

Nesse contexto, junto à Medusa, seriam discutidos, conforme o planejamento, Minotauro, Sátiro, Centauros e Górgonas, seres mitológicos mortais e diferentes por serem meio humanos e meio animais. A proposta do planejamento era descrever as diferenças, porém não foi possível acompanhá-las por meio do registro, pois esse não estava disponível na pasta arquivo. 
O Grupo 6 do período matutino, desde o início do ano, teve três professoras diferentes e, consequentemente, três projetos diferentes. Contudo, foram analisados os planejamentos e o projeto da última professora, por isso foi lido um número menor de documentos.

A pesquisa foi feita em cinco planejamentos e três registros do Grupo 6. Esse grupo trabalhou as propostas que antecederam a Festa das Tradições, a qual tinha como tema "A cultura indígena", sendo possível observar que a professora contemplou a equidade de gênero nas propostas ao possibilitar à criança conhecer a história da primeira indígena a virar cacique no Brasil e, a partir da história, fazer apontamentos sobre a vida das mulheres nas aldeias e como se deu seu posicionamento na sociedade para a garantia dos seus direitos e conquistas.

Ao abordar o papel da mulher na aldeia, foi possível observar, por meio dos registros, a fala das crianças sobre a mulher: "guerreira", "mãe competidora", "forte" e "corajosa"; olhar para a mulher, principalmente indígena que tinha conquistado a posição de cacique, é compreender que a equidade de gênero é possível.

Em outro registro a respeito da mulher indígena (cacique), as crianças apontaram que o papel das mulheres nas aldeias era cuidar da casa e das crianças e cozinhar para os homens. A partir desse apontamento, o planejamento seguinte contemplou a participação feminina na sociedade e sua história por meio dos direitos conquistados pelos movimentos feministas (direitos como o do voto, o da entrada no mercado de trabalho e o da participação dos homens nas tarefas domésticas e na paternidade).

Depois desse planejamento, não foi possível acompanhar o andamento da proposta, já que não apresentava planejamentos e registros, encerrando-se a pesquisa no Grupo 6 matutino.

$\mathrm{Na}$ pesquisa realizada nos planejamentos do Grupo 6 vespertino foi possível analisar seis planejamentos e oito registros da professora regente de sala.Nesses planejamentos foram contemplados diversos enredos explorados em sala, desde a cultura indígena e seus adereços ao cuidado com o meio ambiente. A professora registrou as falas e a participação das crianças. E nas propostas que constam no planejamento foi possível observar o cuidado ao se referir à criança, respeitando sua singularidade e seu tempo de aprendizado e desenvolvimento. Porém, nessas propostas não foi possível observar uma discussão de gênero.

Depois de analisar os planejamentos dos grupos de crianças elaborados pelas professoras regentes, partiu-se para a análise dos planejamentos feitos pelos professores de educação física e auxiliar de ensino.

O professor auxiliar de ensino assume o grupo na ausência ou na hora da atividade da professora regente. Dessa maneira, foi possível analisar oito planejamentos e seis registros, todos articulados ao projeto "Brinquedos, brincadeiras e jogos na Educação Infantil".

O primeiro planejamento apresentado pelo professor estava articulado à proposta da pesquisa feita em casa, a qual apontava as preferências de brincadeiras e brinquedos das crianças. Em forma de gráfico, o professor apresentou a brincadeira preferida das crianças: brincar de boneca. Assim, surgiu a 
proposta de mostrar diferentes bonecas e, a partir disso, planejar apontamentos interessantes para a equidade de gênero.

Descobriu-se que meninos interagiam com mais frequência brincando de boneca, algo que antes da proposta não era visível.

A observação das brincadeiras, na escola pesquisada, tornou possível concluir que as relações entre meninos e meninas podem ser consideradas dados importantes para se construir uma relação não-hierárquica, uma relação de respeito entre os gêneros. Deste modo, o profissional de educação infantil tem papel fundamental para que essas relações possam acontecer de forma livre, sem cobranças quanto a um papel sexual prédeterminado. (FINCO, 2003, p. 7).

Com essa viabilidade, o professor pôde compreender a equidade de gênero e respeitar as diferenças e a singularidade de cada criança nesse espaço de convívio. Dessa maneira, demais planejamentos e registros apontaram as propostas direcionadas por meio das brincadeiras e da confecção dos brinquedos, porém sem dados sobre a discussão de gênero.

Já o professor de educação física elaborou cinco planejamentos e cinco registros. Pôde-se observar nesses planejamentos a prática de separar as crianças em meninas de um lado e meninos de outro para realizar uma proposta pedagógica dinâmica, limitando a interação de meninos e meninas na mesma proposta. Uma das atividades foi tocar instrumentos e dançar: o grupo de meninas tocou e o de meninos dançou e depois os dois grupos se revezaram. Porém, percebeu-se que meninos e meninas não tocaram nem dançaram juntos, o que impossibilitou as influências na constituição das subjetividades das crianças.

Finco (2003, p. 10) descreve:

Porém, quando a professora não reflete sobre sua influência nas relações dos meninos e meninas, ela pode organizar a brincadeira de uma forma a favorecer o sexismo, a prática da professora pode fazer com que as crianças se organizem em grupos distintos de meninas e meninos, sem que haja uma ordem explícita para isso.

Sendo assim, observou-se como o professor estabeleceu nas propostas uma atividade que induzia a uma construção hierárquica de gênero, diferenciando e dificultando a relação das crianças na interação e nas brincadeiras.

\section{Considerações}

A partir desta pesquisa, constatou-se que no PPP não há referências a gênero, ou melhor, há o predomínio de uma linguagem masculina e universal nesse documento. Será que há orientações na rede municipal que contemplem esses aspectos para serem discutidos e incluídos no PPP, de maneira a sinalizar a equidade de gênero tanto nos planejamentos quanto na elaboração do PPP?

No PPP do NEI Campeche, após as pesquisas com as famílias e um estudo da unidade, constatou-se que as datas comemorativas, especialmente o Dia das Mães e o dos Pais, foram trocadas pela Festa da Família, que é comemorada uma vez por ano para confraternizar e socializar, independentemente da constituição familiar. 
Os dados desta pesquisa apontam que só sete planejamentos contemplam a equidade de gênero, considerando-se o número total de 57 planejamentos analisados, o que, de certa forma, leva a pensar que talvez essa questão não seja articulada nos momentos de formação em serviço tanto com professoras, professores e a supervisão.

Por equidade de gênero compreende-se uma melhor aplicação da igualdade de gênero, incluindo as variáveis de classe, etnia, geração, religião etc. Nessa perspectiva busca-se contemplar os critérios de justiça, equivalência e direito à igualdade para as pessoas que se encontram em situações desiguais.

Nesse contexto, entende-se a importância de a escola fomentar o reconhecimento das diferenças e promover ações pedagógicas equitativas, considerando-se as diferentes necessidades das estudantes e dos estudantes.

Louro (1997) descreve que a escola não é apenas um espaço para a transmissão de conhecimentos, mas também a responsabilidade de "fabricar sujeitos" para colaborar com a construção de identidades étnicas, de classe e de gênero.

Nesta pesquisa identificou-se que tanto no PPP quanto nos planejamentos há a necessidade de se reconhecer e visibilizar a figura feminina, já que nas propostas pedagógicas a figura masculina é trabalhada e segue como referência. Apontar a questão de gênero nas propostas da Educação Infantil e contemplar o papel da mulher na sociedade, visibilizando a figura feminina, seja nos documentos, nos planejamentos e/ou no espaço educativo, é importante para a construção da equidade de gênero.

O Currículo da Educação Infantil (FLORIANÓPOLIS, 2015) contempla as discussões de gênero, orientando que as profissionais da educação trabalhem no cotidiano a desconstrução de estereótipos e papéis apropriados para cada gênero.

A educação voltada para a equidade de gênero na Educação Infantil precisa ser pautada no direito da formação de identidade dos sujeitos e, para isso, é preciso romper com os preconceitos, os papéis de gênero, os estereótipos sexuais, as práticas discriminatórias e a heteronormatividade. 


\section{Referências}

BENTO, B. Na escola se aprende que a diferença faz a diferença. Revistas Estudos Feministas, Florianópolis, v. 19, n. 2, p. 549-559, maio/ago. 2011.

BRASIL. Lei n. 9.394, de 20 de dezembro de 1996. Lei de Diretrizes e Bases da Educação Nacional. Brasília: MEC, 1996.

Secretaria de Educação Básica. Diretrizes Curriculares Nacionais para a Educação Infantil.Brasília: MEC/SEB, 2010.

CAMPOS, C. J. G. Método de análise de conteúdo: ferramenta para a análise de dados qualitativos no campo da saúde. Rev. Bras. Enferm., Brasília, v. 57, n. 5, p. 611-614, set./out. 2004.

FELIPE, J. Gênero e sexualidade nas pedagogias culturais: implicações para a educação infantil. In: 22a REUNIÃO ANUAL DA ANPEd, 1999, Caxambu, MG. Anais... Caxambu, 1999.

FINCO, D. Relações de gênero nas brincadeiras de meninos e meninas na educação infantil. ProPosições, Campinas, v. 14, n. 3, p. 89-101, set./dez. 2003. 